doi:10.17659/01.2018.0014

Journal of Case Reports 2018;8(1):54-56

\title{
An Atypical Presentation of Secondary Hyperparathyroidism in the Emergency Department
}

\author{
Vivek Sharma, Ankur Verma, Wasil Rasool Sheikh, Meghna Haldar, Sanjay Jaiswal \\ Department of Emergency Medicine, Max Super Specialty Hospital, Patparganj, I.P. Extension, New Delhi, India.
}

\section{Corresponding Author: \\ Dr. Vivek Sharma \\ Email: drviveksh91@gmail.com}

This is an Open Access article distributed under the terms of the Creative Commons Attribution License (creativecommons.org/ licenses/by/3.0).

Received Accepted Published
October 25, 2017

February 10, 2018

February 20, 2018

\begin{abstract}
Background: Secondary hyper-parathyroidism is over-production of parathyroid hormone secondary to a chronic abnormal stimulus for its production. Typically, this is due to chronic renal failure. Another common cause is vitamin D deficiency which is usually under diagnosed. Pathological fractures due to secondary hyper-parathyroidism are uncommon. Case Report: We present a case of a 27 year old male who presented to the Emergency Department (ED) in shock with complaints of uneasiness, breathing difficulty and generalized body-ache since six hours before arrival. Patient was investigated, resuscitated, provisionally diagnosed as septic shock and rhabdomyolysis and shifted to Intensive Care Unit for further management. Patient later complained of multiple joint pains and underwent X-ray imaging which revealed multiple pathological fractures. He underwent surgical fixation for the fractures and was finally diagnosed with hypo-vitaminosis D, secondary hyper-parathyroidism, hypocalcemia with bilateral pathological shoulder and femur fractures. He was later discharged in a stable condition after 14 days. Conclusion: Secondary hyper-parathyroidism can in rare circumstances present with severe manifestations like shock and multiple pathological bone fractures. Therefore secondary hyper-parathyroidism can be kept in the differential diagnosis while managing such patients.
\end{abstract}

Keywords: Fractures, Hypocalcemia, Kideny Failure, Parathyroid Hormone, Vitamin D Deficiency.

\section{Introduction}

Secondary hyper-parathyroidism is the overproduction of parathyroid hormone secondary to a chronic abnormal stimulus for its production. Typically, this is due to chronic renal failure [1]. Another common cause is vitamin D deficiency which is usually under-diagnosed. Virtually all patients with renal failure have hyperparathyroidism to some degree and their clinical presentation is often that of renal failure. In patients with secondary hyper-parathyroidism due to vitamin $\mathrm{D}$ deficiency, the symptoms are mainly myopathy, bone pain and the patients may have increased risks of fractures. Pathological fractures due to secondary hyper-parathyroidism are uncommon. Here we report a case of seizures and severe shock presenting to the Emergency Department (ED) and diagnosed with pathological fractures and secondary hyper-parathyroidism.

\section{Case Report}

A 27 year old blind male with no known previous co-morbidities was brought to the ED with history of uneasiness, breathing difficulty and generalized bodyache since six hours before arrival. Patient had a history of seizures and fall on the same morning for which he was investigated in another hospital and was neurologically evaluated. He underwent Computed Tomography (CT) and Magnetic Resonance Imaging (MRI) of the brain which were both normal. On examination patient had a heart rate of 124/minute, blood pressure was not 
recordable, respiratory rate of $33 /$ minute, and $\mathrm{SpO}_{2}$ of $100 \%$ on room air. On systemic examination he was conscious, oriented with no focal neurological deficit, pallor was present, small hematoma over the right arm, chest was clear with no added sounds and rest of the systemic examination was unremarkable. He was started with aggressive fluid resuscitation, broad spectrum antibiotics and anticonvulsants. Patient was not fluid responsive and was subsequently started on inotropes. Initial blood gas analysis revealed severe metabolic acidosis with a $\mathrm{pH}$ of 6.930 , bicarbonate of $9.2 \mathrm{meq} / \mathrm{L}$ and lactates of 14. His initial blood work showed a hemoglobin of $7.4 \mathrm{~g} / \mathrm{dL}$, total leucocyte count of $15,200 / \mathrm{mm}^{3}$, procalcitonin level of $23.9 \mathrm{ng} / \mathrm{mL}$, urea of $41.2 \mathrm{mg} / \mathrm{dL}$, creatinine of $1.9 \mathrm{mg} / \mathrm{dL}$ and creatine phosphokinase of 4996 IU/L. Patient was provisionally diagnosed as septic shock with suspected rhabdomyolysis (secondary to seizures) and shifted to the Intensive Care Unit (ICU) for further management. On the $3^{\text {rd }}$ day in ICU, the patient complained of severe joint pains for which $\mathrm{X}$-rays were done. The X-rays revealed the patient to be having comminuted fracture of the right acetabulum, fracture of bilateral femoral necks with displaced bone fragments and comminuted fractures of bilateral neck of humerus [Fig.1-3]. In view of the X-ray findings, the patient's vitamin levels were done which revealed vitamin D of 3.5 $\mathrm{ng} / \mathrm{mL}$, calcium levels of $4.8 \mathrm{mg} / \mathrm{dL}$ and serum parathyroid (PTH) level of $607.2 \mathrm{pg} / \mathrm{mL}$. Patient was finally diagnosed as a case of hypo-vitaminosis $\mathrm{D}$, secondary hyper-parathyroidism, hypocalcemia with bilateral pathological shoulder and femur fractures. He was started on parenteral vitamin D supplementation and underwent surgical fixation of the fractures. The patient was discharged in a stable condition on the $14^{\text {th }}$ day with follow up advice.

\section{Discussion}

Vitamin D deficiency is common in elderly and children, especially in the housebound and geriatric patients [2]. It can cause rickets in children, will

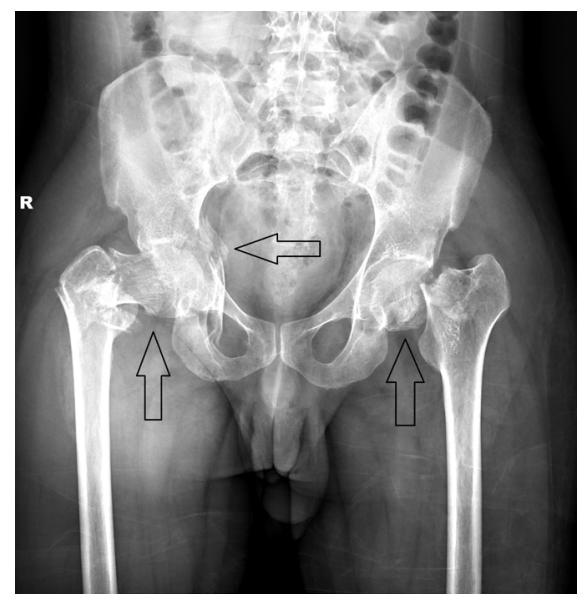

Fig.1: Bilateral femur neck fracture and fracture of the right acetabulum.

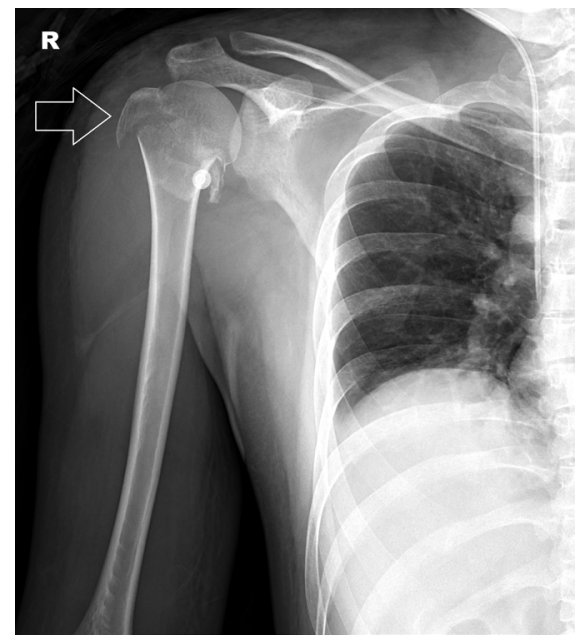

Fig.2: Right sided humerus neck fracture.

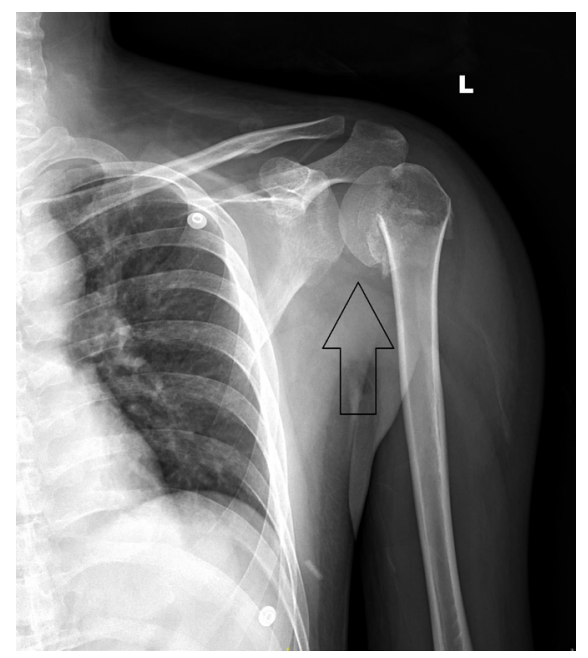

Fig.3: Left sided humerus neck fracture. 
precipitate and exacerbate osteopenia, osteoporosis, fracture in adults and is also associated with increased risk of common cancers, autoimmune diseases and infectious diseases. The synthesis of vitamin D in the skin under the influence of ultraviolet light decreases due to insufficient sunlight exposure and a decreased functional capacity of the skin [2]. Diet low in calcium may cause an increased turnover of vitamin D metabolites and thereby aggravate vitamin D deficiency. The effect of vitamin D depletion in the pathogenesis of secondary hyper-parathyroidism in elderly individuals or in the occurrence of PTH hyperplasia in patients with renal insufficiency is well established. Deficiency of vitamin D causes secondary hyperparathyroidism via its essential action on parathyroid cells, inhibiting parathormone secretion and parathyroid cell proliferation, which can lead to high bone turnover, bone loss, mineralization defect and less commonly myopathy and falls [3]. Down-regulation of parathyroid, vitamin $\mathrm{D}$ and calcium sensing receptors represent critical steps that lead to abnormalities in mineral metabolism; high phosphate, low calcium, and vitamin D deficiency. Disregulation of calcium and phosphate homeostasis leads to decreased renal phosphate excretion, increase serum phosphorus, elevated levels of phosphatonin, fibroblast growth factor 23 and reduced synthesis of calcitriol [4]. These changes result in increase synthesis and secretion of parathyroid hormone and parathyroid hyperplasia, contributing to the development of vicious cycle [3]. Osteitis fibrosis cystica is a highturnover bone disease that stems from elevated
PTH concentrations stimulating osteoclast activity, bone breakdown, and resorption. This can lead to subsequent bone pain and fractures [5].

\section{Conclusion}

Though secondary hyperparathyroidism usually presents with joint pains and myopathies but in rare circumstances the patient may present with severe manifestations like seizures, shock and multiple pathological bone fractures. Therefore secondary hyper-parathyroidism can be kept in the differential diagnosis while managing such patients in the ED.

Contributors: VS: Manuscript editing, patient management; AV: manuscript writing, patient management; WRS,MH,SJ: critical inputs into the manuscript, patient management. VS will act as guarantor. All authors approved the final version of this manuscript.

Funding: None; Competing interests: None stated.

\section{References}

1. Felsenfeld AJ. Considerations for the treatment of secondary hyperparathyroidism in renal failure. J Am Soc Nephrol. 1997;8:993-1004.

2. Lips P. Vitamin D deficiency and secondary hyperparathyroidism in the elderly: consequences for bone loss and fractures and therapeutic implications. Endocrine Reviews. 2001;22:477-501.

3. Slatopolsky E, Brown A, Dusso A. Pathogenesis of secondary hyperparathyroidism. Kidney Intsuppl. 1999;73:s14-s19.

4. Cunningham J, Locatelli F, Rodriguez M. Secondary hyperparathyroidism: pathogenesis, disease progression, and therapeutic options. Clin J Am Soc Nephrol. 2011;6:913-921.

5. Yuen NK, Ananthakrishnan S, Campbell MJ. Hyperparathyroidism of renal disease. Perm J. 2016;20:78-83. 